\title{
Parâmetros eletrocardiográficos em equinos de salto submetidos a um teste de campo
}

Lais Policarpo Macedo ${ }^{[a]}$, Marcela Bucher Binda ${ }^{[a]}$, Fernanda de Almeida Teixeira ${ }^{[a]}$, Renan Silva Carvalho ${ }^{[a]}$, Laura Monteiro Castro Conti ${ }^{[a]}$, Helio Cordeiro Manso Filho ${ }^{[b]}$, Clarisse Simões Coelho ${ }^{[c]}$

\author{
[a] Universidade Vila Velha (UVV-ES), Vila Velha, ES, Brasil \\ [b] Universidade Federal Rural de Pernambuco (UFRPE), Recife, PE, Brasil \\ [c] Universidade Federal da Bahia (UFBA), Salvador, BA, Brasil
}

*Autor correspondente

e-mail: clarissecoelho@yahoo.com.br

\section{Resumo}

Garantir o bem-estar de equinos atletas é crucial. Para tal, torna-se necessário entender os efeitos do exercício sobre parâmetros cardiometabólicos para permitir diferenciar respostas normais e esperadas em animais bem condicionados daquelas oriundas de processos patológicos e/ou falta de condicionamento atlético nas diferentes modalidades. Apesar das várias pesquisas envolvendo equinos atletas, poucas são aquelas com animais de salto treinados em condições tropicais. Para testar a hipótese de que o exercício de salto possa causar modificações compatíveis com o tipo de desafio, foi desenvolvido um trabalho que objetivou avaliar a influência da prova de salto a campo sobre os parâmetros eletrocardiográficos de equinos treinados e adaptados às condições tropicais. Foram usados 12 equinos, raça Brasileiro de Hipismo, com idade média de $11,3 \pm 4,1$ anos e com peso médio de 490,4 $\pm 33,9 \mathrm{~kg}$. Os animais foram avaliados em dois diferentes momentos, no repouso e imediatamente após a prova de salto $(<5 \mathrm{~min})$, usando um equipamento de eletrocardiograma de seis derivações. As variáveis eletrocardiográficas analisadas foram ritmo cardíaco, frequência cardíaca (FC), duração da onda P, do complexo QRS, dos intervalos PR e QT e as amplitudes das ondas P, R e T e análise do QT corrigido de acordo com a fórmula de Bazett (QT $/ \sqrt{R R})$. A prova de salto foi realizada numa pista de areia de $80 \mathrm{~m}$ x $58 \mathrm{~m}$. 0 aquecimento foi feito ao passo e trote por 10 minutos, seguido de cinco obstáculos verticais de alturas progressivas $(0,80 \mathrm{~m}, 0,90 \mathrm{~m}, 1,00 \mathrm{~m})$. Após isso, todos os animais executaram o mesmo percurso com as seguintes especificações: $600 \mathrm{~m}$ de distância total e 12 obstáculos com altura de $100 \mathrm{~cm}$, sendo oito verticais, três oxers paralelas e uma combinação dupla. Durante o percurso, os equinos usaram um sistema de monitoramento da frequência cardíaca acoplado ao GPS (Polar RS800CX). As variáveis foram analisadas quanto à normalidade com o teste Kolmogorov-Smirnov, com comparação entre as médias 
usando teste-t pareado, considerando $\mathrm{P}<0,05$. 0 monitoramento feito pelo frequencímetro demonstrou que os animais executaram a atividade física numa velocidade média de 3,31 \pm 0,31 m/s e FC média de 133,8 \pm 25,7 bpm, completando o percurso em $203,7 \pm 51,0$ segundos. Na análise do ritmo, observou-se $50 \%$ de ritmo sinusal no repouso, com FC média de 31,5 \pm 5,8 bpm, e 75\% de taquicardia sinusal logo após o exercício, com FC média de 76,9 \pm 15,2 bpm. No pós exercício, foi possível observar reduções significativas nas durações da onda $\mathrm{P}(\mathrm{p}<0,0001)$, do complexo QRS $(\mathrm{P}=0,0019)$ e dos intervalos $\mathrm{PR}(\mathrm{P}=0,0002)$ e QT $(\mathrm{P}<0,0001)$, com aumentos significativos na amplitude da onda P $(\mathrm{P}=0,0014)$ e FC $(\mathrm{P}<0,0001) .0$ aumento da FC é esperado em situações de exercício físico e excitação e esse aumento é inversamente correlacionado com a duração dos intervalos PR e QT. O aumento na amplitude da onda P pode ser atribuído a um aumento no tônus simpático. Não foram registradas arritmias cardíacas e todos animais terminaram suas provas com tempo médio e sem fazer faltas no percurso. Foi possível concluir que o teste de salto a campo, usado na presente pesquisa, produziu alterações eletrocardiográficas compatíveis com a intensidade do exercício imposto. Diferenças observadas nas comparações com a literatura podem estar relacionadas com raça, tipo de exercício, condicionamento atlético e condições de criação, reforçando a importância do estabelecimento de respostas normais frente a esse tipo específico de atividade equestre executada em condições tropicais.

Palavras-chave: Cavalo. Frequência cardíaca. Exercício. 